\title{
Serum Cytokine Levels in Major Depressive Disorder and Its Role in Antidepressant Response
}

\author{
Woojae Myung ${ }^{1 *}$, Shinn-Won Lim² ${ }^{2 \star}$, Hye In Woo ${ }^{3}$, Jin Hong Park ${ }^{1}$, \\ Sanghong Shim ${ }^{4}$, Soo-Youn Lee ${ }^{5}$, and Doh Kwan Kim ${ }^{1 凶}$ \\ 1Department of Psychiatry, Samsung Medical Center, Sungkyunkwan University School of Medicine, Seoul, Republic of Korea \\ 2SAIHST, Sungkyunkwan University School of Medicine, Samsung Medical Center, Seoul, Republic of Korea \\ ${ }^{3}$ Department of Laboratory Medicine, Samsung Changwon Hospital, Sungkyunkwan University School of Medicine, Changwon, Republic of Korea \\ ${ }^{4}$ Center for Clinical Research, Samsung Biomedical Research Institute, Samsung Medical Center, Seoul, Republic of Korea \\ ${ }^{5}$ Department of Laboratory Medicine and Genetics, Samsung Medical Center, Sungkyunkwan University School of Medicine, Seoul, Republic of Korea
}

Objective Cytokines have been reported to have key roles in major depressive disorder (MDD). However, much less is known about cytokines in MDD and antidepressant treatment due to the diversity of cytokines and the heterogeneity of depression. We investigated the levels of cytokines in patients with MDD compared with healthy subjects and their associations with antidepressant response.

Methods We investigated the changes of several cytokines (eotaxin, sCD40L, IL-8, MCP-1alpha, TNF-alpha, INF-gamma and MIP1alpha) by Luminex assay in 66 patients with MDD and 22 healthy controls. The antidepressant response was assessed by 17 -item Hamilton Rating Scale for Depression.

Results We found the levels of sCD40L ( $\mathrm{p}=0.001)$, IL-8 ( $\mathrm{p}=0.004)$ and MCP-1 ( $\mathrm{p}=0.03)$ of healthy controls were significantly higher than those of depressive patients. However, the level of eotaxin and TNF-alpha were not associated with MDD. In addition, we found the level of MCP-1 was significantly changed after antidepressant treatment $(\mathrm{p}=0.01)$.

Conclusion These findings suggest the roles of cytokines in MDD are complex, and could vary according to the individual characteristics of each patient. Further studies regarding the relationship between cytokines and MDD will be required.

Psychiatry Investig 2016;13(6):644-651

Key Words Antidepressants, Depression, Immune system.

\section{INTRODUCTION}

Major depressive disorder (MDD) is the most common of serious psychiatric disorders. ${ }^{1}$ The connection of MDD and the dysregulation of the immune system has become apparent. ${ }^{2-6}$ It has been found that cytokines may play an important role in this connection. ${ }^{7}$ Cytokines are a diverse group of

Received: October 20, 2015 Revised: February 2, 2016

Accepted: March 28, 2016 Available online: May 20, 2016

$\triangle$ Correspondence: Doh Kwan Kim, MD, PhD

Department of Psychiatry, Samsung Medical Center, Sungkyunkwan University School of Medicine, 81 Irwon-ro, Gangnam-gu, Seoul 06351, Republic of Korea Tel: +82-2-3410-3582, Fax: +82-2-3410-0941, E-mail: paulkim@skku.edu $\triangle$ Correspondence: Soo-Youn Lee, MD, PhD

Department of Laboratory Medicine and Genetics, Samsung Medical Center, Sungkyunkwan University School of Medicine, 81 Irwon-ro, Gangnam-gu, Seoul 06351, Republic of Korea

Tel: +82-2-3410-1834, Fax: +82-2-3410-2719, E-mail: suddenbz@skku.edu

*These authors contributed equally to this work.

(a) This is an Open Access article distributed under the terms of the Creative Commons Attribution Non-Commercial License (http://creativecommons.org/licenses/by$\mathrm{nc} / 3.0$ ) which permits unrestricted non-commercial use, distribution, and reproduction in any medium, provided the original work is properly cited. small proteins that are regarded as the hormones of the immune system. ${ }^{8}$ Cytokines affect brain function by supporting neuronal integrity, neurogenesis, and synaptic remodeling. ${ }^{9}$ Cytokines also have an effect on neurotransmitter systems and the neurocircuit, inducing behavioral alternations. ${ }^{10-13}$

Numerous studies have reported the increase of proinflammatory cytokines: IL-1, IL-6, tumor necrosis factor (TNF)alpha, and prostaglandin E2 (PGE2), in major depressive disorder. ${ }^{14-17}$ A study with a cerebrospinal fluid assay reported that IL- 6 concentrations correlate with the severity of depression. ${ }^{18}$ A recent meta-analysis showed that the concentrations of cytokines (IL-1beta, IL-6, and TNF-alpha) are decreased after antidepressant treatment. ${ }^{19}$

A series of meta-analyses confirmed the correlation between pro-inflammatory cytokines (TNF-alpha and IL-6) and $\mathrm{MDD} ;{ }^{7,14,20}$ however, the role of other cytokines in MDD remains unclear. In addition, ethnicity may play an important role in the relationship between the levels of cytokines and MDD, and relatively few studies have been conducted in the 
Asian population. ${ }^{7}$ In this study, we investigated cytokines that have been known to have a role in psychiatric disorder in Korean population with MDD.

Our primary hypothesis is that the levels of cytokines would differ between the patients with MDD and healthy subjects. Secondary, we tested their associations with antidepressant responsiveness and the severity of depression. Additionally, we investigated their changes due to antidepressant medication.

\section{METHODS}

\section{Subjects}

Sixty-six Korean patients with MDD were recruited from the clinical trials program of the Samsung Medical Center Geropsychiatry and Affective Disorder Clinics (Seoul, Korea). Patients fulfilled the Diagnostic and Statistical Manual of Mental Disorders, Fourth Edition, Text Revision (DSM-IVTR), criteria for major depressive episode. ${ }^{21,22}$ Diagnoses were confirmed by a board certified psychiatrist on the basis of an initial clinical interview and a structured research interview. ${ }^{23,24}$ A minimum baseline 17-item Hamilton Rating Scale for Depression (HAM-D) score of 15 was required. ${ }^{25}$ Exclusion criteria were pregnancy, significant medical conditions, abnormal laboratory baseline values, unstable psychiatric features (e.g, suicide attempt), histories of alcohol or drug dependence, seizure, neurological illnesses, including significant cognitive impairment, or concomitant Axis I psychiatric disorders (schizophrenia, bipolar affective disorder, primary diagnosis of adjustment disorder, or posttraumatic stress disorder). No patient met the DSM-IV criteria for the specifier 'Severe with Psychotic Features', and none had received psychotropic medication with the current episode. In addition, no patients had received psychotropic medication within 4 weeks. Twentytwo healthy volunteers without histories of psychiatric illness were recruited by advertisement. A psychiatrist screened the control group with an interview and then biochemical tests were administered. Volunteers with a family history of mood disorders or evidence of inflammatory illness (flu, allergic disease, or dermatitis) or immunopathies were not included. The protocol was approved by the ethics review board of Samsung Medical Center, Seoul, Korea.

\section{Procedures}

Patients received an antidepressant monotherapy for 6 weeks. SSRIs [escitalopram $(n=31)$, sertraline $(n=2)$, paroxetine $(n=$ $11)$, fluoxetine $(n=1)]$ and mirtazapine $(n=21)$ were chosen by clinician based on the anticipated adverse effects and the symptomatic characteristics of patients. Dose titration was completed within two weeks to check compliance. The HAM$\mathrm{D}$ scores ${ }^{26}$ were obtained by a single trained rater every two weeks. A response was defined as a decrease in HAM-D score of $50 \%$ or more at week $6 .{ }^{27}$ The rater and laboratory workers were blinded to the purpose of this study. In addition, cytokine data were not disclosed to the rater and the HAM-D scores were not exposed to the laboratory workers.

\section{Determination of cytokine levels}

Through a literature survey based on their likely importance for the psychiatric disorder, we initially selected 19 cytokines (exotaxin, sCD40L, IL-1a, IL-1b, IL-2, IL-4, IL-7, IL-8, IL-10, IL-12, FGF-2, MCP-1, TNF-alpha, alpha2-macroglobulin, Apoprotein AI, Apoprotein E, C3, INF-gamma and MIP-1alpha). We evaluated the analytical performance of the commercially available assay kits, Human Cytokine/Chemokine Magnetic Bead Panel 1 and Human Neurodegenerative Disease Panel 1 (Millipore, Billerica, MA, USA). Seven cytokines (eotaxin, sCD40L, IL-8, MCP-1, TNF-alpha, INF-gamma, and MIP-1alpha) were finally selected in the consideration of precision, calibration range and the limit of quantification of the assay method. These inflammatory markers have been shown to be relevant in psychiatric diseases. ${ }^{7,14,15,28,29}$ Venous blood was drawn at baseline and at week 6 . After serum isolation by centrifugation, the samples were stored at $-80^{\circ} \mathrm{C}$. Inflammatory markers were measured using $25 \mu \mathrm{L}$ of serum with a Luminex 200 analyzer (Luminex Corporation, Austin, TX, USA) with the Human Cytokine/Chemokine Magnetic Bead Panel 1.

Markers for which more than $10 \%$ of the samples had values below limit of quantitation (LOQ) at baseline were not included in the analysis. ${ }^{30}$ Two cytokines were excluded from the analysis because they frequently had values below the LOQ (53.4\% for INF-gamma, and 67.0\% for MIP-1alpha). Eotaxin (none), sCD40L (none), IL-8 (1.1\%), MCP-1 (none), TNF-alpha (8.0\%) were included in the analysis. For each marker retained for analysis, samples with undetectable values were given the value zero.

\section{Statistical analysis}

Continuous variables are presented as median and interquartile range. The Wilcoxon rank-sum test was employed to compare these variables between healthy control subjects and patients or the responsive and non-responsive groups. Categorical variables were presented as frequencies and proportions, and tested with Fisher's exact test. Median regression was employed to compare non-normally distributed continuous variables adjusting for other variables. The Wilcoxon signedrank test was used to compare the cytokine values of pre- and post-antidepressant treatment. Relationships between two continuous variables were tested by Spearman's correlation analysis. p-values were corrected by Bonferroni's correction 
for the multiple association tests of cytokines and noted as corrected $\mathrm{p}$. All differences were considered to be significant at $\mathrm{p}<0.05$. Statistical analysis was undertaken using STATA SE 10.0 for Windows (College Station, TX, USA).

\section{RESULTS}

\section{Clinical and demographic characteristics}

Clinical and demographic characteristics are shown in Table

1. There were no notable differences between the control sub- jects and patients with respect to age and sex. The rate of response to antidepressants was 40 of 66 patients (60.6\%). A family history of depression was present in $15.2 \%$ of the patients. The median baseline HAM-D score was 19 (interquartile range: 17-21), indicating moderate to severe depression. Age, sex, episode number, current episode duration, age at onset, and baseline HAM-D score were not associated with antidepressant responsiveness. In addition, choice of drug had no effect on the rate of response $(\mathrm{p}>0.05)$. The median HAM-D score gradually decreased from 19 to 9 (week 2: $15,{ }^{12-18}$ week 4: $12,{ }^{9-17}$

Table 1. Clinical and demographic characteristics of subjects

\begin{tabular}{|c|c|c|c|c|}
\hline \multirow[b]{2}{*}{ Variable } & \multirow{2}{*}{$\begin{array}{l}\text { Control subjects } \\
\qquad(\mathrm{N}=22)\end{array}$} & \multicolumn{2}{|c|}{ Depressive patients $(\mathrm{N}=66)$} & \multirow[b]{2}{*}{ Statistics and $\mathrm{p}$} \\
\hline & & $\begin{array}{l}\text { Drug responsive } \\
\qquad(\mathrm{N}=40)\end{array}$ & $\begin{array}{l}\text { Drug non-responsive } \\
\qquad(\mathrm{N}=26)\end{array}$ & \\
\hline \multirow[t]{2}{*}{ Female, no. (\%)* } & $16(72.7 \%)$ & \multicolumn{2}{|c|}{$50(75.8 \%)$} & $\mathrm{p}=0.78$ \\
\hline & & $28(70.0 \%)$ & $22(84.6 \%)$ & $\mathrm{p}=0.24$ \\
\hline \multirow[t]{2}{*}{ Age, year ${ }^{\dagger}$} & $66.5(64,69)$ & \multicolumn{2}{|c|}{$68(60,73)$} & $\mathrm{Z}=-0.34, \mathrm{p}=0.73$ \\
\hline & & $69.5(61.5,73)$ & $68(55,72)$ & $\mathrm{Z}=-0.91, \mathrm{p}=0.36$ \\
\hline \multirow[t]{2}{*}{ Family history of depression (\%) } & & \multicolumn{2}{|c|}{$10(15.2 \%)$} & $\mathrm{p}=1$ \\
\hline & & $5(12.5 \%)$ & $5(19.2 \%)$ & \\
\hline \multirow[t]{2}{*}{ Episode, no $^{\dagger}$} & & \multicolumn{2}{|c|}{$2(1,3)$} & $\mathrm{Z}=1.54, \mathrm{p}=0.12$ \\
\hline & & $2(1,2)$ & $2(2,3)$ & \\
\hline \multirow[t]{2}{*}{ Current episode duration, months } & & \multicolumn{2}{|c|}{$3(2,12)$} & $\mathrm{Z}=0.70, \mathrm{p}=0.48$ \\
\hline & & $3.5(2,10.5)$ & $3(2,13)$ & \\
\hline \multirow[t]{2}{*}{ Age at onset, year ${ }^{\dagger}$} & & \multicolumn{2}{|c|}{$59(48,67)$} & $\mathrm{Z}=-1.27, \mathrm{p}=0.20$ \\
\hline & & $60.5(51,67)$ & $55(32,62)$ & \\
\hline \multirow[t]{2}{*}{ HAM-D baseline ${ }^{\ddagger}$} & & \multicolumn{2}{|c|}{$19(17,21)$} & $\mathrm{Z}=1.10, \mathrm{p}=0.27$ \\
\hline & & $18(17,21)$ & $20(17,22)$ & \\
\hline
\end{tabular}

Data are given as median and interquartile range. *Fisher's exact test was used, ${ }^{\dagger}$ Wilcoxon rank-sum test was used. HAM-D: Hamilton depression rating score

Table 2. Baseline serum concentrations of cytokines in major depressive patients $(\mathrm{N}=66)$ and healthy controls $(\mathrm{N}=22)$

\begin{tabular}{|c|c|c|c|c|c|c|}
\hline \multirow{2}{*}{$\begin{array}{l}\text { Variable } \\
(\mathrm{pg} / \mathrm{mL})\end{array}$} & \multirow{2}{*}{$\begin{array}{l}\text { Control subjects } \\
\qquad(\mathrm{N}=22)\end{array}$} & \multicolumn{2}{|c|}{ Depressive patients $(\mathrm{N}=66)$} & \multirow{2}{*}{$\begin{array}{l}\text { Statistics } \\
(\mathrm{Z})^{*}\end{array}$} & \multirow{2}{*}{$\begin{array}{c}\text { Corrected } \\
\mathrm{p}^{*}\end{array}$} & \multirow{2}{*}{$\begin{array}{c}\text { Corrected } \mathrm{p} \text { after } \\
\text { adjusting for covariates }\end{array}$} \\
\hline & & $\begin{array}{l}\text { Drug responsive } \\
\qquad(\mathrm{N}=40)\end{array}$ & $\begin{array}{l}\text { Drug non-responsive } \\
\qquad(\mathrm{N}=26)\end{array}$ & & & \\
\hline \multirow[t]{2}{*}{ Eotaxin } & $135(113,172)$ & \multicolumn{2}{|c|}{$135(104,190)$} & 0.24 & 1 & 1 \\
\hline & & $136.5(109.5,198.5)$ & $133(99,174)$ & -0.60 & 1 & 1 \\
\hline \multirow[t]{2}{*}{ sCD40L } & $44950(28800,66700)$ & \multicolumn{2}{|c|}{$19700(5990,40800)$} & 3.07 & 0.01 & 0.001 \\
\hline & & $15100(4965,41600)$ & $23450(8460,40800)$ & 0.74 & 1 & 1 \\
\hline \multirow[t]{2}{*}{ IL-8 } & $15.65(10.7,21.2)$ & \multicolumn{2}{|c|}{$10.01(7.2,13.6)$} & 3.09 & 0.01 & 0.004 \\
\hline & & $10.25(7.37,13.8)$ & $9.87(6.78,13)$ & 0.16 & 1 & 1 \\
\hline \multirow[t]{2}{*}{ MCP-1 } & $462.5(373,584)$ & \multicolumn{2}{|c|}{$342(235,407)$} & 3.58 & 0.002 & 0.03 \\
\hline & & $350.5(228,456)$ & $304(260,371)$ & -0.93 & 1 & 1 \\
\hline \multirow[t]{2}{*}{ TNF-alpha } & $5.46(3.7,7.64)$ & \multicolumn{2}{|c|}{$5.02(2.9,7.18)$} & 0.61 & 1 & 1 \\
\hline & & $5.02(2.9,7.18)$ & $4.86(2.72,9.18)$ & 0.14 & 1 & 1 \\
\hline
\end{tabular}

Data are given as median and interquartile range. ${ }^{*}$ Wilcoxon rank-sum test was used; with Bonferroni correction for five cytokines, ${ }^{\dagger}$ Median regression analysis was used after adjusting for age and sex; with Bonferroni correction for five cytokines. sCD40L: soluble CD40-ligand, IL-8: interleukin 8, MCP-1: monocyte chemoattractant protein-1, TNF-alpha: tumor necrosis factor alpha 
week 6: $\left.9^{6-14}\right)$.

\section{Serum cytokine levels and diagnosis}

Baseline plasma concentrations of cytokines in the participants are shown in Table 2 and Figure 1. The median value of sCD40L of healthy controls was higher than that of depressive patients $(44950 \mathrm{pg} / \mathrm{mL}, 2880-66700 \mathrm{pg} / \mathrm{mL}$ vs 19700 , $5990-40800 \mathrm{pg} / \mathrm{mL}$, respectively; corrected $\mathrm{p}=0.01$ ). This difference was maintained after adjusted for age and sex [adjusted $\mathrm{p}=0.001,95 \%$ confidence interval $(\mathrm{CI})=14036.24$ 43266.99]. IL- 8 (corrected $\mathrm{p}=0.01$ ) and MCP- 1 (corrected $\mathrm{p}=$ 0.002 ) were significantly associated with a diagnosis of major depressive disorder. The levels of IL-8 and MCP-1 were higher in healthy controls when compared to depressive patients. These associations were robust after adjusted for age and sex (IL-8: adjusted $\mathrm{p}=0.004,95 \% \mathrm{CI}=3.09-10.73, \mathrm{MCP}-1$ : adjusted $\mathrm{p}=0.03,95 \% \mathrm{CI}=44.71-254.38$ ). The levels of these cytokines did not differ with sex, old age $(>60)$, late onset $(>60)$ and recurrence (number of episode $\geq 2$ ).

\section{Serum cytokine levels and antidepressant treatment}

We found no association between baseline cytokine concentration and antidepressant response (Table 2). In addition, changes of cytokine concentrations after 6 weeks of antide- pressant treatment were not associated with responsiveness.

We found the level of MCP-1 significantly increased after antidepressant treatment (corrected $\mathrm{p}=0.01$ ) (Table 3 ). This association was observed in both the response (corrected $\mathrm{p}=$ 0.04 ) and non-response (corrected $\mathrm{p}=0.04$ ) groups. Moreover, the significance of difference in MCP- 1 concentration between the healthy controls and depressive patients disappeared after antidepressant treatment $(\mathrm{p}=0.06,95 \% \mathrm{CI}=-2.34-168.80)$.

\section{Serum cytokine levels and severity of depression}

There was no significant correlation between HAM-D score and cytokine concentration at baseline and at week 6 . The HAM-D score changes did not correlate with cytokine level changes after antidepressant treatment.

\section{DISCUSSION}

In this study, we investigated the association between depression response to antidepressant medication, and several inflammatory cytokines. We identified the association between diagnosis of depression and three cytokines (sCD40L, IL-8 and MCP-1), and we found that the level of MCP-1 was significantly increased after antidepressant treatment.

CD40 ligand (CD40L) is a transmembrane glycoprotein struc-
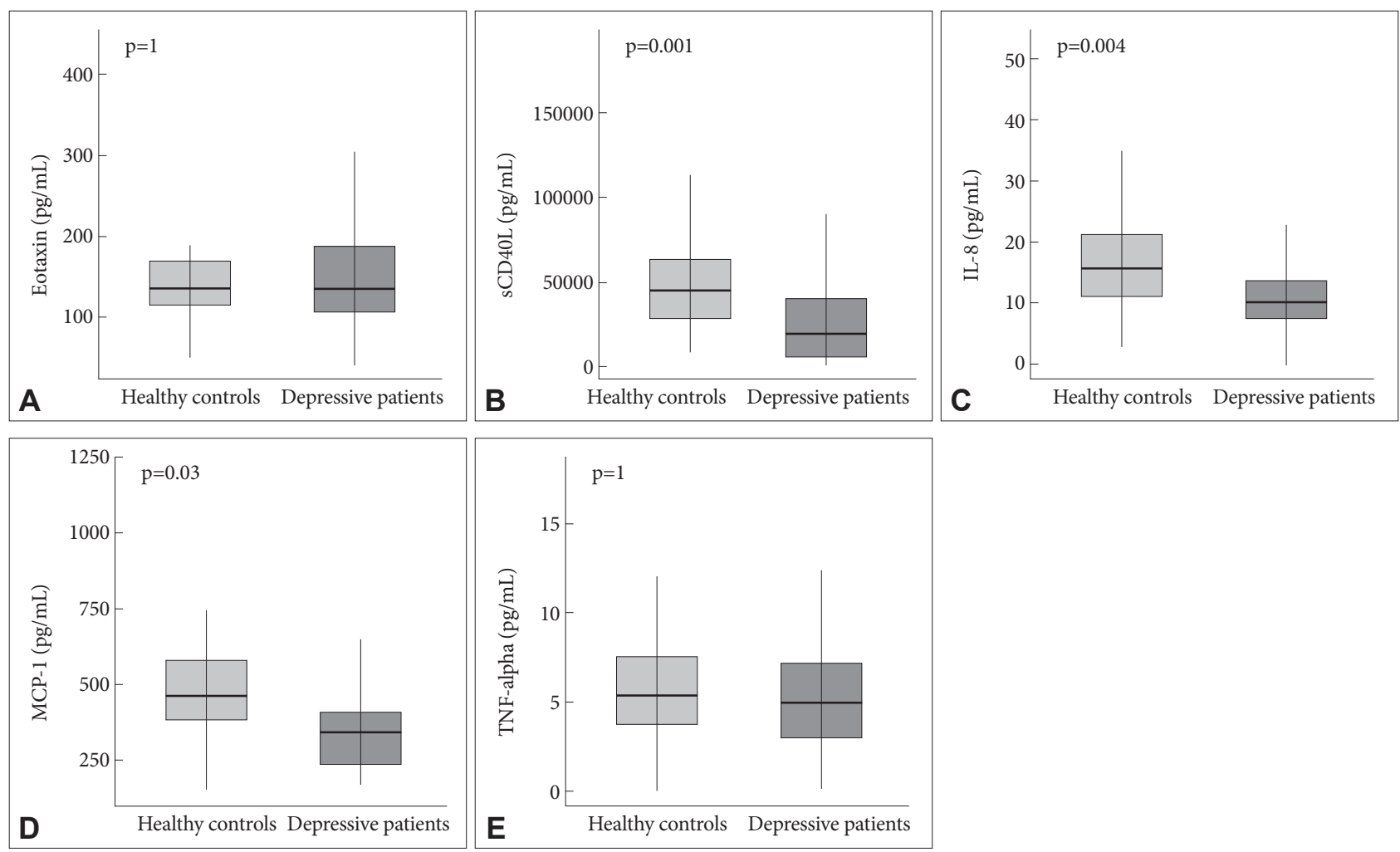

Figure 1. Box plot: baseline plasma concentrations of cytokine in major depressive patients and healthy controls. A: Eotaxin, B: SCD40L, C: IL-8, D: MCP-1, and E: TNF-alpha. p-values were calculated by median regression analysis after adjusted for age and sex; Bonferroni correction was used for the five cytokines. SCD40L: soluble CD40-ligand, IL-8: interleukin 8, MCP-1: monocyte chemoattractant protein-1, TNF-alpha: tumor necrosis factor alpha. 
Table 3. Serum concentrations of cytokines at baseline and at 6 weeks after the antidepressant treatment in major depressive patients $(\mathrm{N}=66)^{*}$

\begin{tabular}{lcccc}
\hline \multicolumn{1}{c}{ Cytokine $(\mathrm{pg} / \mathrm{mL})$} & At baseline & At 6 weeks & Statistics $(\mathrm{Z})$ & Corrected $\mathrm{p}$ \\
\hline Eotaxin & $135(112.5,178)$ & $147(106,189)$ & -1.82 & 0.34 \\
sCD40L & $24800(8390,47350)$ & $18900(5010,51700)$ & 0.17 & 1 \\
IL-8 & $11.3(7.9,15.2)$ & $11.15(7.28,14.8)$ & -0.61 & 1 \\
MCP-1 & $368(261.5,469.5)$ & $375(286,518)$ & -3.19 & 0.01 \\
TNF-alpha & $5.33(3.33,7.24)$ & $5.09(3.25,7.72)$ & -0.04 & 1 \\
\hline
\end{tabular}

Data are given as median and interquartile range. ${ }^{*}$ Wilcoxon signed-rank test was used; with Bonferroni correction for five cytokines. sCD40L: soluble CD40-ligand, IL-8: interleukin 8, MCP-1: monocyte chemoattractant protein-1, TNF-alpha: tumor necrosis factor alpha

turally related to TNF-alpha. ${ }^{31} \mathrm{CD} 40$ ligand exists in two forms, membrane-bound and soluble (sCD40L). The protein binds to the CD40 receptor and induces the production of cytokines, connective tissue degrading enzymes, and upregulates the inflammatory response. ${ }^{32}$ This interaction between CD40 and CD40L is known to be an important step in the priming of helper T-cells. ${ }^{33}$ Leo et al..$^{28}$ reported that SCD40L levels increased in patients with MDD compared with controls and also found a correlation between the level of sCD40L and the severity of depression as assessed by the HAM-D (Table 4). In addition, they reported that mood improvement with SSRI treatment was associated with a reduction in sCD40L ${ }^{28}$ Another study reported by Neubauer et al. ${ }^{34}$ showed a concordant result, that $\mathrm{CD} 40 \mathrm{~L}$ was elevated in patients with depression as compared to controls. However, our results showed a diametrical association; the level of $\mathrm{SCD} 40 \mathrm{~L}$ in healthy controls was higher than that of depressive patients.

We can speculate several reasons for the discrepancy. The first is the difference of the illness duration. Previous studies were conducted during the first episode of depression; however, in our study, depressive patients (72.7\%) were experiencing their second or a later episode of MDD. It has been suggested that cytokine-induced neurochemical alterations might vary with the number of depressive episodes. ${ }^{35}$ Griffiths et al. ${ }^{36}$ suggested that the recurrence of depression might involve chronic cytokine activation. Further studies for CD40L in recurrent depression are needed. Another possible factor for such discrepancy is the proportion of old age patients. Previous studies that reported an elevated level of CD40L in depressive patients included mostly middle-aged patients. ${ }^{28,34}$ Our patients were mostly elderly (age $>60$ years, $74.2 \%$ ), and a large portion of them had late-onset illness (age of first onset $>60$ years, $45.5 \%$ ). Several studies have suggested that the age at onset can vary in different subtypes of depression, especially in terms of heritability. ${ }^{37,38}$ In addition, previous studies reported that proinflammatory cytokines increase in healthy elderly people, ${ }^{39-41}$ although, we could not find a significant relationship between age, age on onset and $\mathrm{sCD} 40 \mathrm{~L}$ in our study subjects. Another consideration is that our study was conducted in Asian population. Further studies with clinically homogeneous samples in recurrent depression and in an elderly group or various ethnic groups will be required.

Previous studies that investigated the association between IL-8 and depression reported inconsistent results (Table 4). Simon et al. found elevated level of IL-8 in depression, ${ }^{42}$ but three other studies found no significant association. ${ }^{19,43,44}$ In contrast, Lehto et al. reported a decreased level of IL-8 in depression, which was in agreement with our results. ${ }^{45} \mathrm{IL}-8$ has been known as a neutrophil chemotatic factor; ${ }^{46}$ however, the detailed functions of this cytokine are complex. High circulating levels of IL-8 act to decreased the infiltration of neutrophils to the inflammatory site, performing pro- or anti- inflammatory roles, depending on the concentration. ${ }^{8}$ Therefore, there was a possibility that the association between IL-8 level and depression could be changed according to the study population.

Relatively few studies have investigated the association between MCP-1 and depression. Lehto et al..$^{45}$ and Grassi-Oliveria et al. ${ }^{47}$ found that depression was associated with lower MCP-1 concentrations compare to healthy controls, but others reported contrary results (Table 4). ${ }^{42,48}$ Our results, finding lower levels of IL-8 and MCP-1, suggest a reduced level of chemokines in depression. The detailed mechanism for this association is unclear. The neuroprotective function of neuronal chemokines, ${ }^{49,50}$ and their dopaminergic activity-enhancing effect in the central nervous system could be possible explanations. However, limitations to our interpretation should be noted because our results were obtained from peripheral blood.

Sutcigil et al. ${ }^{48}$ reported that the level of MCP-1 decreased after sertraline treatment. However, we found an increase in MCP-1 levels following antidepressant treatment. The major difference between our result and the previous study is the number of episodes that patients experienced. Sutcigil et al. included only first episode patients in their study, but, as noted above, most of our study patients were recurrent depression. Although, we could not find a significant relationship between episode number and the level of MCP-1 in our 
Table 4. Summary of previous studies that investigated the association between depression and the significant cytokines in our study

\begin{tabular}{|c|c|c|}
\hline \multirow{2}{*}{ Study } & \multicolumn{2}{|c|}{ Results } \\
\hline & Association with depression & Association with antidepressant response \\
\hline \multicolumn{3}{|l|}{ sCD40L } \\
\hline Our study & $\begin{array}{l}\text { sCD40L levels decreased in MDD patients } \\
\text { compared with controls }\end{array}$ & No significant association \\
\hline Leo et al. ${ }^{28}$ & $\begin{array}{l}\text { sCD40L levels increased in MDD patients } \\
\text { compared with controls }\end{array}$ & $\begin{array}{l}\text { Response with SSRI treatment was associated } \\
\text { with a reduction in } \mathrm{SCD} 40 \mathrm{~L}\end{array}$ \\
\hline Neubauer et al. ${ }^{34}$ & $\begin{array}{l}\text { sCD40L levels increased in MDD patients } \\
\text { compared with controls }\end{array}$ & Not investigated \\
\hline \multicolumn{3}{|l|}{ IL-8 } \\
\hline Our study & $\begin{array}{l}\text { IL-8 levels decreased in MDD patients compared } \\
\text { with controls }\end{array}$ & No significant association \\
\hline Simon et al. ${ }^{42}$ & $\begin{array}{l}\text { IL-8 levels increased in MDD patients compared } \\
\text { with controls }\end{array}$ & Not investigated \\
\hline Eller et al. ${ }^{19}$ & No significant association & No significant association \\
\hline Mikova et al. ${ }^{43}$ & No significant association & No significant association \\
\hline O’Brien et al. ${ }^{44}$ & No significant association & Not investigated \\
\hline Lehto et al. ${ }^{45}$ & $\begin{array}{l}\text { IL-8 levels decreased in MDD patients compared } \\
\text { with controls }\end{array}$ & Not investigated \\
\hline \multicolumn{3}{|l|}{ MCP-1 } \\
\hline Our study & $\begin{array}{l}\text { MCP-1 levels decreased in MDD patients compared } \\
\text { with controls }\end{array}$ & MCP-1 levels increased after antidepressant treatment \\
\hline Lehto et al. ${ }^{45}$ & $\begin{array}{l}\text { MCP-1 levels decreased in MDD patients compared } \\
\text { with controls }\end{array}$ & Not investigated \\
\hline $\begin{array}{l}\text { Grassi-Oliveira } \\
\text { et al. }{ }^{47}\end{array}$ & $\begin{array}{l}\text { MCP-1 levels decreased in MDD patients compared } \\
\text { with controls }\end{array}$ & Not investigated \\
\hline Sutcigil et al. ${ }^{48}$ & $\begin{array}{l}\text { MCP-1 levels increased in MDD patients compared } \\
\text { with controls }\end{array}$ & MCP-1 levels decreased after sertraline treatment. \\
\hline
\end{tabular}

sCD40L: soluble CD40-ligand, IL-8: interleukin 8, MCP-1: monocyte chemoattractant protein-1, TNF-alpha: tumor necrosis factor alpha

study subjects, the difference in the antidepressants used may have also contributed to this discordance. Interestingly, the directions of change in both studies were toward those of the healthy controls. The study of Sutcigil et al. showed a higher level of MCP-1 in depressive patients compare to healthy controls, and the difference decreased after treatment. We found a decreased level of MCP-1 in depressive patients, and it was normalized toward the level of healthy controls after antidepressant treatment. The antidepressant effect of COX-2 inhibitors that block production of prostaglandin $\mathrm{E}$ and proinflammatory cytokines were investigated in several clinical trials. ${ }^{51-53}$ In one study, combination therapy of COX-2 inhibitor (celecoxib) and sertraline reduced level of serum IL-6 levels in patients with MDD, and reduction of the severity of depressive symptoms and reduction of the level of serum IL-6 were significantly correlated. ${ }^{53}$ Further studies that investigate the effect of the combination treatment with COX-2 inhibitor on the level of MCP-1 could be helpful.

We found no association between the level of eotaxin or
TNF-alpha and depression. These negative results were inconsistent with recent studies for eotaxin ${ }^{47,54}$ and a meta-analysis of TNF-alpha. ${ }^{7}$ However, our findings are in line with other reports conducted in elderly patients. ${ }^{55-57}$ Additional studies adjusted for age with larger sample sizes are required.

Several limitations were present in our study. Our sample was relatively small. The cross-sectional design for association between depression and cytokines precludes conclusions about causality. We could not consider potential variables, such as smoking, lifetime use of anti-inflammatory or analgesic drugs, minor medical illness, and body mass index. Another consideration is that because our patients were mostly elderly due to the clinical setting of patient enrollment, the generalizability of our results to other age groups may be limited.

Overall, we found the associations between sCD40L, IL-8, MCP-1, and depression. In addition, we showed that the level of MCP-1 was significantly increased after antidepressant treatment. Our results imply that the characteristics of study population are important, and the roles of cytokines in de- 
pression are sophisticated and nuanced. The relationship between cytokines and depression remains to be clarified. Further studies concerning covariance with age and recurrence are required.

\section{Acknowledgments}

This work was supported by a grant of the Korean Health Technology R\&D Project from the Ministry of Health \& Welfare, Republic of Korea (A110339, HI14C2071). These funding sources were not involved in the creation of the study protocol, data analysis, or in writing the manuscript.

\section{REFERENCES}

1. Kessler RC, Chiu WT, Demler O, Merikangas KR, Walters EE. Prevalence, severity, and comorbidity of 12-month DSM-IV disorders in the National Comorbidity Survey Replication. Arch Gen Psychiatry 2005; 62:617-627.

2. Capuron L, Miller AH. Immune system to brain signaling: neuropsychopharmacological implications. Pharmacol Ther 2011;130:226-238.

3. Leonard BE. The concept of depression as a dysfunction of the immune system. Curr Immunol Rev 2010;6:205-212.

4. Leonard BE, Song C. Stress and the immune system in the etiology of anxiety and depression. Pharmacol Biochem Behav 1996;54:299-303.

5. Miller AH. Neuroendocrine and immune system interactions in stress and depression. Psychiatr Clin North Am 1998;21:443-463.

6. Song C, Dinan T, Leonard BE. Changes in immunoglobulin, complement and acute phase protein levels in the depressed patients and normal controls. J Affect Disord 1994;30:283-288.

7. Liu Y, Ho RC, Mak A. Interleukin (IL)-6, tumour necrosis factor alpha (TNF-alpha) and soluble interleukin-2 receptors (sIL-2R) are elevated in patients with major depressive disorder: a meta-analysis and metaregression. J Affect Disord 2012;139:230-239.

8. Kronfol Z, Remick DG. Cytokines and the brain: implications for clinical psychiatry. Am J Psychiatry 2000;157:683-694.

9. Yirmiya R, Goshen I. Immune modulation of learning, memory, neural plasticity and neurogenesis. Brain Behav Immun 2011;25:181-213.

10. Capuron L, Miller AH. Cytokines and psychopathology: lessons from interferon-alpha. Biol Psychiatry 2004;56:819-824.

11. Dantzer R, Kelley KW. Twenty years of research on cytokine-induced sickness behavior. Brain Behav Immun 2007;21:153-160.

12. Dunn AJ, Swiergiel AH. The role of cytokines in infection-related behavior. Ann N Y Acad Sci 1998;840:577-585.

13. Dunn AJ, Swiergiel AH, de Beaurepaire R. Cytokines as mediators of depression: what can we learn from animal studies? Neurosci Biobehav Rev 2005;29:891-909.

14. Dowlati Y, Herrmann N, Swardfager W, Liu H, Sham L, Reim EK, et al. A meta-analysis of cytokines in major depression. Biol Psychiatry 2010; 67:446-457.

15. Howren MB, Lamkin DM, Suls J. Associations of depression with C-reactive protein, IL-1, and IL-6: a meta-analysis. Psychosom Med 2009;71: 171-186.

16. Lieb J, Karmali R, Horrobin D. Elevated levels of prostaglandin E2 and thromboxane B2 in depression. Prostaglandins Leukot Med 1983;10: 361-367.

17. Maes M, Bosmans E, Meltzer HY, Scharpe S, Suy E. Interleukin-1 beta: a putative mediator of HPA axis hyperactivity in major depression? Am J Psychiatry 1993;150:1189-1193.

18. Lindqvist D, Janelidze S, Hagell P, Erhardt S, Samuelsson M, Minthon L, et al. Interleukin-6 is elevated in the cerebrospinal fluid of suicide attempters and related to symptom severity. Biol Psychiatry 2009;66:287-292.

19. Eller T, Vasar V, Shlik J, Maron E. Pro-inflammatory cytokines and treatment response to escitalopram in major depressive disorder. Prog Neuropsychopharmacol Biol Psychiatry 2008;32:445-450.
20. Hannestad J, DellaGioia N, Bloch M. The effect of antidepressant medication treatment on serum levels of inflammatory cytokines: a meta-analysis. Neuropsychopharmacology 2011;36:2452-2459.

21. American Psychiatric Association, American Psychiatric Association Task Force on DSM-IV. Diagnostic and Statistical Manual of Mental Disorders: DSM-IV-TR (4th Text Version Ed). Washington, DC: American Psychiatric Association; 2000.

22. Kim H, Lim SW, Kim S, Kim JW, Chang YH, Carroll BJ, et al. Monoamine transporter gene polymorphisms and antidepressant response in koreans with late-life depression. JAMA 2006;296:1609-1618.

23. Kim DK, Lim SW, Lee S, Sohn SE, Kim S, Hahn CG, et al. Serotonin transporter gene polymorphism and antidepressant response. Neuroreport 2000;11:215-219.

24. Myung W, Lim SW, Kim S, Kim H, Chung JW, Seo MY, et al. Serotonin transporter genotype and function in relation to antidepressant response in Koreans. Psychopharmacology (Berl) 2013;225:283-290.

25. Hamilton M. A rating scale for depression. J Neurol Neurosurg Psychiatry 1960;23:56-62.

26. Hamilton M. Development of a rating scale for primary depressive illness. Br J Soc Clin Psychol 1967;6:278-296.

27. Kato M, Serretti A. Review and meta-analysis of antidepressant pharmacogenetic findings in major depressive disorder. Mol Psychiatry 2010; 15:473-500.

28. Leo R, Di Lorenzo G, Tesauro M, Razzini C, Forleo GB, Chiricolo G, et al. Association between enhanced soluble CD40 ligand and proinflammatory and prothrombotic states in major depressive disorder: pilot observations on the effects of selective serotonin reuptake inhibitor therapy. J Clin Psychiatry 2006;67:1760-1766.

29. Suarez EC, Krishnan RR, Lewis JG. The relation of severity of depressive symptoms to monocyte-associated proinflammatory cytokines and chemokines in apparently healthy men. Psychosom Med 2003;65: 362-368.

30. Wang XS, Shi Q, Shah ND, Heijnen CJ, Cohen EN, Reuben JM, et al. Inflammatory markers and development of symptom burden in patients with multiple myeloma during autologous stem cell transplantation. Clin Cancer Res 2014;20:1366-1374.

31. Freedman JE. CD40-CD40L and platelet function: beyond hemostasis. Circ Res 2003;92:944-946.

32. Schonbeck U, Mach F, Sukhova GK, Murphy C, Bonnefoy JY, Fabun$\mathrm{mi} \mathrm{RP}$, et al. Regulation of matrix metalloproteinase expression in human vascular smooth muscle cells by $\mathrm{T}$ lymphocytes: a role for $\mathrm{CD} 40$ signaling in plaque rupture? Circ Res 1997;81:448-454.

33. Schonbeck U, Mach F, Libby P. CD154 (CD40 ligand). Int J Biochem Cell Biol 2000;32:687-693.

34. Neubauer H, Petrak F, Zahn D, Pepinghege F, Hagele AK, Pirkl PA, et al. Newly diagnosed depression is associated with increased betathromboglobulin levels and increased expression of platelet activation markers and platelet derived CD40-CD40L. J Psychiatr Res 2013;47: 865-871.

35. Anisman H, Merali Z. Cytokines, stress, and depressive illness. Brain Behav Immun 2002;16:513-524.

36. Griffiths J, Ravindran AV, Merali Z, Anisman H. Dysthymia: a review of pharmacological and behavioral factors. Mol Psychiatry 2000;5:242-261.

37. Nierenberg AA, Trivedi MH, Fava M, Biggs MM, Shores-Wilson K, Wisniewski SR, et al. Family history of mood disorder and characteristics of major depressive disorder: a STAR*D (sequenced treatment alternatives to relieve depression) study. J Psychiatr Res 2007;41:214-221.

38. Power RA, Keers R, Ng MY, Butler AW, Uher R, Cohen-Woods S, et al. Dissecting the genetic heterogeneity of depression through age at onset. Am J Med Genet B Neuropsychiatr Genet 2012;159b:859-868.

39. Fagiolo U, Cossarizza A, Scala E, Fanales-Belasio E, Ortolani C, Cozzi E, et al. Increased cytokine production in mononuclear cells of healthy elderly people. Eur J Immunol 1993;23:2375-2378.

40. Molteni M, Della Bella S, Mascagni B, Coppola C, De Micheli V, Zulian C, et al. Secretion of cytokines upon allogeneic stimulation: effect 
of aging. J Biol Regul Homeost Agents 1994;8:41-47.

41. Paganelli R, Scala E, Quinti I, Ansotegui IJ. Humoral immunity in aging. Aging (Milano) 1994;6:143-150.

42. Simon NM, McNamara K, Chow CW, Maser RS, Papakostas GI, Pollack $\mathrm{MH}$, et al. A detailed examination of cytokine abnormalities in Major Depressive Disorder. Eur Neuropsychopharmacol 2008;18:230233.

43. Mikova O, Yakimova R, Bosmans E, Kenis G, Maes M. Increased serum tumor necrosis factor alpha concentrations in major depression and multiple sclerosis. Eur Neuropsychopharmacol 2001;11:203-208.

44. O’Brien SM, Scully P, Fitzgerald P, Scott LV, Dinan TG. Plasma cytokine profiles in depressed patients who fail to respond to selective serotonin reuptake inhibitor therapy. J Psychiatr Res 2007;41:326-331.

45. Lehto SM, Niskanen L, Herzig KH, Tolmunen T, Huotari A, Viinamaki $\mathrm{H}$, et al. Serum chemokine levels in major depressive disorder. Psychoneuroendocrinology 2010;35:226-232.

46. Kunkel SL, Standiford T, Kasahara K, Strieter RM. Interleukin-8 (IL-8): the major neutrophil chemotactic factor in the lung. Exp Lung Res 1991;17:17-23.

47. Grassi-Oliveira R, Brieztke E, Teixeira A, Pezzi JC, Zanini M, Lopes RP, et al. Peripheral chemokine levels in women with recurrent major depression with suicidal ideation. Rev Bras Psiquiatr 2012;34:71-75.

48. Sutcigil L, Oktenli C, Musabak U, Bozkurt A, Cansever A, Uzun O, et al. Pro- and anti-inflammatory cytokine balance in major depression: effect of sertraline therapy. Clin Dev Immunol 2007;2007:76396.

49. de Haas AH, van Weering HR, de Jong EK, Boddeke HW, Biber KP. Neuronal chemokines: versatile messengers in central nervous system cell interaction. Mol Neurobiol 2007;36:137-151.
50. Madrigal JL, Leza JC, Polak P, Kalinin S, Feinstein DL. Astrocyte-derived MCP-1 mediates neuroprotective effects of noradrenaline. J Neurosci 2009;29:263-267.

51. Muller N, Schwarz MJ, Dehning S, Douhe A, Cerovecki A, GoldsteinMuller B, et al. The cyclooxygenase- 2 inhibitor celecoxib has therapeutic effects in major depression: results of a double-blind, randomized, placebo controlled, add-on pilot study to reboxetine. Mol Psychiatry 2006;11:680-684.

52. Akhondzadeh S, Jafari S, Raisi F, Nasehi AA, Ghoreishi A, Salehi B, et al. Clinical trial of adjunctive celecoxib treatment in patients with major depression: a double blind and placebo controlled trial. Depress Anxiety 2009;26:607-611.

53. Abbasi SH, Hosseini F, Modabbernia A, Ashrafi M, Akhondzadeh S. Effect of celecoxib add-on treatment on symptoms and serum IL-6 concentrations in patients with major depressive disorder: randomized double-blind placebo-controlled study. J Affect Disord 2012;141:308-314.

54. Magalhaes PV, Jansen K, Stertz L, Ferrari P, Pinheiro RT, da Silva RA, et al. Peripheral eotaxin-1 (CCL11) levels and mood disorder diagnosis in a population-based sample of young adults. J Psychiatr Res 2014; 48:13-15.

55. Brambilla F, Maggioni M. Blood levels of cytokines in elderly patients with major depressive disorder. Acta Psychiatr Scand 1998;97:309-313.

56. Brambilla F, Monteleone P, Maj M. Interleukin-1beta and tumor necrosis factor-alpha in children with major depressive disorder or dysthymia. J Affect Disord 2004;78:273-277.

57. Diniz BS, Teixeira AL, Talib LL, Mendonca VA, Gattaz WF, Forlenza OV. Increased soluble TNF receptor 2 in antidepressant-free patients with late-life depression. J Psychiatr Res 2010;44:917-920. 